\title{
DE LA VINIFICACIÓN A LA ETNOMERCANCÍA. PROCESO DE CONVERSIÓN DE ACTIVIDADES AGRARIAS EN PROPUESTA TURÍSTICA EN TOCONAO, NORTE DE CHILE
} From Vinification to Ethnocommodity. Conversion Process

\author{
of Agricultural Activities into Touristic Model in Toconao, Northern Chile
}

\section{IGNACIO HERRERA*}

Fecha de recepción: 24 de mayo de 2019 - Fecha de aprobación: 28 de agosto de 2019

\section{Resumen}

El artículo aborda las transformaciones de la vinicultura de la localidad lickanantay de Toconao, en el norte de Chile, como respuesta a la vertiginosa diversificación del rubro turístico en el desierto de Atacama. Por medio del caso del vino toconar se visibilizan procesos de adaptación y emprendimientos indígenas en los poblados atacameños para actuar en la economía turística, centralizada desde la década de 1990 en empresas afuerinas. En ellos, los habitantes de las comunidades han articulado productos y lugares endémicos a un modelo económico rentable, donde los insumos circulan como rutas turísticas y etnomercancías. La investigación reconstruye el proceso de conversión de tradiciones agrarias en mercancías a través de une serie de datos etnográficos y testimonios que muestran las disputas y las adaptaciones del poblado indígena para percibir las rentas del turismo.

Palabras clave: lickanantay; vinicultura; turismo; etnomercancía.

\section{Abstract}

The article focuses on the transformations of local viniculture in the Lickanantay community of Toconao in the Northern Chile, as a response to the fast diversification of the tourism industry in the Atacama Desert. The Toconao wine makes visible a process of adaptation and indigenous entrepreneurship of towns in Atacama to a touristic economy, which has been centralized in foreign enterprises since the nineties. In this process, the habitants of these communities have articulated endemic products and places into a profitable economic model, where the items circulate like touristic routes and ethnocommodities. The research rebuilds the conversion process of agrarian traditions into merchandise, through a series of ethnographic data and testimonies, to point out the disputes and adaptations of the indigenous population to receive tourism income.

Keywords: lickanantay; viniculture; tourism; ethnocommodity.

*Antropólogo. Investigador independiente, Santiago de Chile. El artículo forma parte de la investigación conducente a la tesis de Licenciatura en la Escuela de Antropología de la Universidad Academia de Humanismo Cristiano. Correo-e: iherrera. olguin@gmail.com 


\section{Introducción}

En este artículo se describe el proceso experimentado por el poblado de Toconao durante la instalación acelerada del turismo trasnacional en la cuenca del salar de Atacama desde finales del siglo XX. A lo largo de este desarrollo ha quedado patente la actual tendencia de las localidades de la región a dirigir el tratamiento del turismo, teniendo en cuenta lo avasallador e invasivo de la experiencia de San Pedro de Atacama. Esto se suma a procesos de determinación en los que se exaltan rasgos diferenciadores del repertorio homogéneo de "lo atacameño" (Bustos, 2015). Uno de los ejemplos más notables de este último fenómeno es el cambio toponímico de estas comunidades, cuyos miembros ahora se llaman a sí mismos "lickanantay", denominación que otorga mayor densidad histórica y establece un discurso que evidencia un vínculo de larga data con los valles desérticos (Bolados, 2014).

Dado que una buena parte de la literatura sobre el tema en Atacama la Grande se centra en los cascos centrales de San Pedro de Atacama, esta investigación se enfoca en el pueblo-oasis de Toconao pues urge profundizar en una antropología del turismo que observe los efectos de esta actividad económica en localidades con tratamiento periférico. De este modo, se postula que estos poblados reorganizan su vida cotidiana, política y económica a partir de la relación con el turismo trasnacional. En la reciente década han emergido iniciativas entre los toconares tendientes a una mayor participación en el área productiva del turismo, cosa que es posible gracias a una serie de reivindicaciones territoriales y patrimoniales en lo que va de este siglo.
Lo ocurrido en Toconao es parte de una disposición de varias comunidades de la cuenca del salar en redoblar esfuerzos para incorporar objetos y prácticas alicaídas a una narrativa actualizada en un contexto turistificado (Bustos, 2015). Siguiendo el trabajo de Bustos, lo pertinente aquí es desentrañar los procesos de transformación de las mencionadas prácticas que son reelaboradas entre lo cotidiano y las influencias globales. Persiguiendo tal objetivo, esta investigación revisa el establecimiento de categorías en el sistema turístico a partir de las cuales se definen una serie de políticas locales, en las que los pobladores adquieren protagonismo en la mercantilización de su propia tradición.

En específico, se trae a colación la tradición vitivinícola de oasis en cuanto funciona como ejemplo in situ de adaptación de prácticas locales al modelo de negocios del turismo. Así se revela la capacidad de los grupos indígenas de elaborar una serie de estrategias de articulación en contextos desfavorables, utilizando los mismos resquicios abiertos por un sistema desigual (Castillo, Espinoza \& Campos, 2017). En este caso se expone cómo la industria del viaje se instala sin muchas posibilidades de participación para la población oriunda, la cual, con los años, se arma de herramientas para competir por las ganancias del turismo a través de la prestación de servicios y la comercialización de mercancías con marca étnica. Esto no quiere decir que de este esquema no surjan otras formas de dependencia o situaciones desiguales.

Para resolver los objetivos planteados, la metodología empleada en la investigación es de tipo cualitativa y se dirige a identificar habitantes actuales de Toconao que han estado vinculados, en la última década, directa o indirectamente con 
el rubro turístico y/o las actividades prediales al menos. Los testimonios de estas personas son recogidos mediante la modalidad de entrevista en profundidad, conversaciones sistematizadas luego en categorías de análisis histórico y situacional. Dichas comunicaciones personales se utilizaron para enmarcar un proceso cronológico, el cual se complementa con material bibliográfico e información etnográfica ${ }^{1}$ expresiva de situaciones de alteridad, usos de los espacios y formas de trabajo emergidas de las relaciones mediadas por el turismo en Toconao.

Ya que lo pertinente es la revisión del proceso de turistificación de las prácticas prediales y los objetos asociados a ellas, la información recabada es analizada a través de un esquema diacrónico y constructivista. Con este prisma se ordenan situaciones de alteridad histórica, cimentadas dialécticamente entre aspectos locales y cotidianos y contextos trasnacionales. De esta forma, se propone que de la concatenación progresiva de oposiciones y adaptaciones de la localidad con la industria turística acelerada surgen elementos que condensan la tradición y la práctica local. Estos son vistos como experiencias y objetos capaces de circular en el mercado del turismo y son categorizados bajo la idea de etnomercancía, sobre la cual es meritorio detenerse.

\section{Reflexiones sobre la etnomercancía}

La construcción teórica sobre la emergencia de etnomercancías en el mercado trasnacional de lo exótico se atribuye a John Comaroff y Jean Comaroff (2009), quienes cuestionaron el devenir de la etnicidad en la sociedad de consumo masivo y del espectáculo. A partir de sus estudios en África y Norteamérica, establecieron una línea teórica que observa la capacidad de los grupos étnicos de proyectarse bajo las reglas del consumo globalizado, es decir, de condensar el ethos étnico en materia mercantil. Es a través de este modelo de reproducción de la cultura que los grupos indígenas sopesan su herencia cultural en mercados como el turismo. Al hacerlo declaran también un derecho real de propiedad sobre un patrimonio determinado, del cual serían dueños para reproducirlo y mercantilizarlo (Álvarez, 2018).

Se vislumbra así un ejercicio colectivo de proyección memorial sobre objetos producidos por comunidades indígenas, los cuales alcanzan un estatus significativo en mercados donde las categorías étnicas son valoradas y demandadas (Escalona, 2016). En la base del ejercicio memorial se encuentra el modelo de construcción de la tradición, según el cual los grupos humanos constantemente reinterpretan aspectos de su pasado de acuerdo a propósitos contingentes, estableciendo así su propia continuidad histórica y planificación futura (Hobsbawm, 2012). Al sopesar elementos pasados según la fórmula de Hobsbawm, las sociedades fijan una tradición determinada, la cual pueden proyectar de formas innovadoras y situacionales.

Con este modelo de base, ¿es posible que la proyección memorial determine la generación de valor de ciertos objetos? Para responder tal cuestionamiento se parte de la noción de mercancía, a la que en su forma más simple ya se le ha atribuído una serie de características sublimes, es decir, valores supuestamente objetivos e intercambiables (Jappe, 2016). Como principio general a toda mercancía, al adquirir un objeto de dotación étnica, digamos artesanía, su comprador entra en una relación 
social compleja donde las cosas adquieren un valor según el trabajo que supuestamente contienen (ídem). Debe destacarse, no obstante, el carácter supuesto de todo este proceso, pues el valor no existe como tal, sino solo en el acto mismo de intercambiar, es decir, que existe una relación especular entre mercancías donde estas se presumen como objetivamente equivalentes (Žižek, 2003).

En la relación especular entre bienes comienza la operación fetichista en la que el trabajo humano se reduce a formas de valor que propician su circulación y que se establecen por la sumatoria abstracta entre el valor de uso del bien y el tiempo que lleva producirlo en situaciones supuestamente "normales" (Jappe, 2016). Pero, en general, los compradores no se detienen en estas entelequias, pues actúan convencidos de que responden a imperativos prácticos cuando en realidad están envueltos en la forma de socialización del mercado, donde son compelidos a reconocer como objetiva esta dimensión imaginaria del valor, sin la cual el intercambio no sería posible (Žižek, 2003). El hecho de que todo el proceso opere de forma inconsciente en los sujetos demuestra la efectividad del fetichismo de la mercancía.

Sin embargo, en la compraventa del souvenir turístico, el valor de uso parece difuminarse, pues en apariencia es solamente decorativo, aunque contiene un misterioso "algo más" que llama a su adquisición por ciertos consumidores. Este aspecto de la mercancía es bien sintetizado por Slavoj Žižek en la película de la directora Sophie Fiennes (2012), The Pervert's Guide to Ideology. En ella se explican sus cualidades metafísicas, que poco tienen que ver con las características objetivas del producto. Estas bondades invisibles e ideológicas hacen deseables las cosas pues le dan significados asociados al bienestar, el ecologismo o cualquier otro que el comercio sea capaz de reproducir.

Al situar la impregnación de significados supramateriales en mercados como el turismo, donde se demanda cultura y exotismo, no es extraño que los bienes que circulan en él también se vean atribuidos de tales valores (Escalona, 2016), lo cual entraña una operación fetichista aún más intencionada y explícita que en el general de las mercancías. En este sentido, Escalona propone que en estos intercambios se traslapa una serie de cualidades a la producción étnica, es decir, ocurre una "sobrefetichización de la mercancía, o una fetichización de otro tipo o de otro estrato: una transformación del objeto-valor en valores adheridos. Tenemos así objetos entendidos como mercancías y/o vehículos simbólicos de identidades imaginadas y/o de estilos artísticos singulares" (ídem, pp. 276-277).

Al estar abierta la posibilidad de que las localidades proyecten hacia el mercado sus patrones de gusto y valores estéticos, las comunidades indígenas y tribales han volcado su economía y política hacia la tendencia global de la producción turística y artística (Escalona, 2016)). Esta estrategia de reproducción de la cultura también conlleva riesgos, pues si bien significa un reconocimiento existencial de la otredad constitutiva, este se logra exaltando cierto exotismo romántico que los consumidores, en este caso turistas, pagan por adquirir (Comaroff \& Comaroff, 2009). Como bien advierten los Comaroff, en ningún caso el mercado es el arca que salvará a la diversidad cultural del diluvio de la alineación, pues siempre existe la posibilidad de distorsionar el sentido de las prácticas y los objetos, o de que emerjan formas insólitas de subalternidad. Implica, así, una serie de oportunidades y peligros. 
Al seguir la línea teórica de la etnomercancía se asume la capacidad de generar capital económico a partir de la diversidad cultural (Comaroff \& Comaroff, 2009), pero respecto de este punto el lector ya está al tanto sobre los supuestos ficticios que atañen a la mercancía, de los cuales el artefacto étnico no está exento. De modo que decir que la otredad es la materia prima de la etnomercancía es más un recurso analítico que una realidad, pues en lo práctico sigue siendo un producto de la naturaleza trasformado por el trabajo y la inventiva. Entonces, la diferencia fundamental de la etnomercancía con el resto de los bienes intercambiables es la sumatoria de un valor agregado a la fórmula especular de atribución de valores y trabajo a las cosas.

Este misterioso "algo más" que los pueblos indígenas están trayendo a la palestra turística infunde a los objetos producidos por ellos una identidad que se supone antigua, culturalmente específica y producto de un grupo humano igualmente determinado (Escalona, 2016). En el caso atacameño este proceso ha implicado una búsqueda consciente de elementos culturales diferenciadores por parte de las comunidades, incluso financiados por fomentos al emprendedor indígena por parte de empresas mineras (Bustos, 2015). Cabe precisar que la incorporación a la economía de la identidad no anula los vínculos históricos, emocionales y políticos que los comuneros reivindican detrás de los procesos de mercantilizar la diferencia (Comaroff \& Comaroff, 2009).

En síntesis, el análisis de la etnomercancía no puede estar separado del proceso histórico y contextual que le da nacimiento, donde se oponen aspectos locales y globales. Es un proceso de atribuir elementos del pasado y la tradición comunitaria a ciertos objetos, los cuales forman o formaron parte de la producción local, que ahora adquieren valor agregado o una apreciación especial en mercados específicos como el turismo. Tal es el caso de la tradición y la producción vinícola desértica, la cual retoma elementos del pasado y es incorporada a la economía del turismo.

\section{Situación general del vino y el turismo en la región}

En esta década, los toconares se han deslizado sigilosamente hacia el rubro vinícola, cuestión posibilitada tanto por el estado del mercado nacional del vino como por el sistema turístico del norte chileno. A pesar de que el turismo se instala sin participación atacameña, los pobladores logran incorporarse con progresiva lucidez y determinación a su faz productiva, alcanzando cierta participación económica y política en un modelo de desarrollo claramente impuesto (Bustos, 2015). Este hecho se manifiesta en el surgimiento de propuestas de turismo étnico, rural y/o cultural durante este siglo, con lo cual las comunidades del salar alcanzan un rol protagónico y se alzan como coadministradoras de la Reserva Nacional Los Flamencos y de museos comunitarios (Bolados, 2014).

Surge entonces un abanico de emprendimientos indígenas, entre los cuales el enoturismo fue imprevisto, pues la región atacameña está lejos de esa imagen idílica de valles verdes adjudicada a la vinoteca nacional, sino que es una cuenca hiperárida donde el desierto de Atacama alcanza su mayor profundidad (Villagrán, Castro, Sánchez, Romo, Latorre \& Hinojosa, 1998). Es un desierto intenso que se extiende entre cordones montañosos como un lienzo de tierra pintado con salares blancos 
y quebrado por hendiduras fértiles donde abundan árboles, vegas y humedales (Bustos, 1999). Entre este oasis y a 2.400 msnm está Toconao, antiguamente construido en piedra y en terrazas en suave pendiente para aprovechar las corrientes endorreicas para la agricultura (ídem), la misma que hoy le permite encauzarse hacia el ambicioso rubro del vino.

Para comprender la situación actual de la bebida insigne de Chile, se recurre a la última edición de la cronología de José del Pozo (2014), quien expone el carácter oligopólico de la industria viñatera nacional, la que históricamente se ha concentrado en el Valle Central. Desde mediados de los noventa, sin embargo, el aumento de la producción vinícola del país y la variación de consumidores han motivado la multiplicación de nuevos terruños, lo que "obedece a la búsqueda de lugares que puedan aportar nuevos sabores al vino, empleando cepas más variadas y aprovechando condiciones climáticas diferentes" (ídem, p. 247). Esta tendencia se expresa en la zonificación vitícola establecida por decreto $^{2}$, la que obliga a las viñas a especificar el valle de origen de la vid de acuerdo a un catálogo de áreas que la norma establece.

Tanto los criterios de zonificación como el surgimiento de nuevos valles y pequeños productores expuestos por Del Pozo ignoran a la cuenca del salar como depositaria de tradición vitivinícola ${ }^{3}$, quizás por lo reciente de la producción tecnificada o la poca (o nula) visibilidad en los escaparates de circulación nacional. Aun así, los vinos toconares han logrado una presencia creciente en el contexto turístico del desierto de Atacama, uno perteneciente a una red transfronteriza de experiencias y productos, donde compiten y cooperan agentes públicos, privados, regiones, localidades, en pos de repartirse los beneficios del tráfico de viajeros (Amilhat-Szary \& Guyot, 2009).

Esta red turística de valores paisajísticos es uno de los combustibles del motor económico de la cuenca del salar de Atacama. Actúa en conjunto con el rubro minero anclado en la extracción de litio y, más recientemente, el interés científico depositado en la radioastronomía (Gundermann, González \& Durston, 2018). En la región desértico-andina convergen distintos procesos trasnacionales que se manifiestan en instituciones concretas, las cuales son más que solo industrias económicas pues "participan y se constituyen en actores relevantes de la vida y el desarrollo de las poblaciones y de los grupos donde realizan actividades extractivas" (Bolados, 2014, p. 433). Asimismo, el turismo no solo incentiva el mercado regional, sino que se emplaza como un ente supraeconómico que influye en la vida cotidiana de las comunidades implicadas en su órbita desde su anclaje en la década de 1990.

Desde entonces el poblado de San Pedro de Atacama y sus alrededores han sido promovidos como destino arqueológico, contemplativo y de nuevas experiencias, que atrae a segmentos diversificados de consumidores de turismo (Gundermann, 2004). Mientras ocurría esto, las poblaciones de la cuenca fueron reconocidas como pueblos originarios a través de una serie de leyes y políticas patrimonializadoras, avaladas tanto por la academia como por organismos no gubernamentales (Bolados \& Boccara, 2015). Con la etnificación intensa de los pueblos atacameños y el rápido avance del turismo, surge un sistema de relaciones donde aparecen diferencias tajantes entre el segmento indígena y los afuerinos atraídos por el desarrollo del mercado del viaje (Gundermann, et al., 2018). 
Dichas diferencias no son solo categoriales sino económicas, pues mientras las poblaciones originarias desempeñan un papel como prestadores de servicios al turismo, los recién llegados "gringos" y chilenos no indígenas comienzan a ocupar las áreas más lucrativas del quehacer (Gundermann, et al., 2018; Gundermann, 2004). Esto lleva a que las comunidades del salar proyecten en el turismo un sentido de propiedad sobre recursos culturales y patrimoniales, y que surjan figuras corporativas en esta población, sin dejar de lado la reivindicación étnica (Bustos, 2015). De ahí que el estatus de atacameño, ya sea de forma deliberada o incidental, implique también desplegar la etnicidad hacia la defensa de derechos de propiedad territorial e intelectual (Morales, 2016).

Dado que paulatinamente se va abriendo un mayor rango de acción de los pueblos atacameños/lickanantay en el turismo, surge entre estos una dispersión de narrativas no intrínsecamente étnicas, pero que forman parte de su actual configuración identitaria (Gundermann, et al., 2018). Varios de estos repertorios de significado brotan del marco de relaciones mediadas por el turismo trasnacional y establecen así nuevos criterios diferenciadores entre los diversos actores de esta industria económica. Dicho así, los pobladores de Toconao intensifican o manifiestan otredades variadas al participar en la red turística. El hecho de hacer evidentes estas singularidades inaugura un proceso donde son incorporadas a emprendimientos rentables.

La vitalización de las actividades agrarias en el mercado turístico y enológico de la cuenca se origina en un contexto específico de adversidad económica y territorial, junto al progresivo empoderamiento indígena en la repartición del beneficio turístico. Ya conocido a nivel general el proceso de turistificación de los poblados del salar de Atacama, se describe a continuación una visión más localista basada en la construcción histórica de categorías diferenciadoras, las cuales serán la base para la propuesta turística toconar.

\section{La experiencia sanpedrina}

El turismo no siempre fue visto como un horizonte promisorio para los pueblos de la cuenca del salar, pues desde que la empresa del viaje trazó a Toconao como parte de sus circuitos, revivió antiguos resquemores insertos en la memoria de sus pobladores. Los encuentros entre sistema turístico y nativos rememoran en las comunidades receptoras sensaciones de servilismo y viejos rencores, basados en la relación asimétrica que se establece entre la población oriunda y los viajeros (Fuller, 2008). En el caso de la localidad toconar, el desfile de tours operadores trae formas de discriminación, unas veces soterrada y otras evidente, cuestión que tensiona la relación de los habitantes con los recién llegados, a quienes perciben como invasores y racistas:

Si estas empresas que están en San Pedro de Atacama hubieran dicho "oye, hagamos parte a la gente de Toconao, apoyemos en este aspecto", no sé, tantas formas de trabajo que podrían habernos tomado en cuenta. Ellos se pusieron del otro lado, egoístamente. [...] Cuando yo llegué a Toconao, me puse a trabajar los sectores turísticos y me empecé a dar cuenta realmente cómo los mismos guías trataban a las niñas que trabajaban como indias. $Y$ las niñas se escondían, mujeres más jóvenes que yo se escondían, tenían vergüenza (M. Mondaca, comunicación personal, 19 enero 2019).

La sensación de invasión se intensificó durante la década de 1990, momento en que 
el turismo se asienta y centraliza en San Pedro de Atacama, pues se estableció una dinámica poco sostenible para la población local, quienes experimentaron un alza general de precios, contaron con poca participación en los beneficios del rubro y fueron testigos de la degradación medioambiental del territorio (AmilhatSzary \& Guyot, 2009). Este acondicionamiento del poblado a los niveles de consumo de los viajeros, generalmente provenientes de países desarrollados, resultó en la segregación de la población nativa de los espacios tradicionales (ídem), razón por la cual los sanpedrinos se vieron replegados a los ayllus, las periferias y poblaciones en urbes del Norte Grande.

Las condiciones de la marginación atacameña del poblado y el tratamiento vejatorio recibido de parte de tours operadores y agencias generan una expresión de alteridad que surge de las relaciones desiguales del sistema turístico y que por estos días se torna un dicho popular entre los toconares: "no convertirse en un segundo San Pedro de Atacama”. Este principio, altamente nombrado en las iniciativas turísticas comunitarias e individuales de Toconao declara una distancia con la experiencia sanpedrina al establecer lineamientos estratégicos enfocados en evitar la entrada de agentes afuerinos a territorios de propiedad local. Dichas estrategias fueron desplegadas a comienzos de este siglo con la disputa de la Comunidad de Toconao con el holding hotelero Explora S.A.:

Toconao también tiene su directiva, la Comunidad de Toconao. Ellos empezaron a ser muy estrictos, entonces el hotel cinco estrellas que es Explora intentó unir a Toconao también. O sea, era un punto que ellos también querían explotar turísticamente. [...] ellos vinieron y compraron un terreno en la quebrada de Jere, para hacer un hotel cinco estrellas. Entonces la Comunidad de Toconao les dijo que no podían, porque las aguas no las iban a ceder. Aquí todas las aguas arti- ficiales están a nombre de la Comunidad, y es un territorio que tiene su deslinde, que también está a nombre de la Comunidad. Entonces solamente la Comunidad puede explotarlo en la parte agrícola o en otras áreas. Entonces no pudieron ellos hacer el hotel Explora (M. Mondaca, comunicación personal, 19 enero 2019).

El triunfo comunitario en materia turística es un antecedente claro de cómo se desarrollaría el rubro en Toconao durante las décadas venideras, con un ostracismo declarado y localista. Este es un hermetismo estratégico que evita la explotación afuerina de un territorio que los toconares aprecian como propiedad ancestral. Esta política de puertas cerradas fija normas de exclusividad para la población lickanantay de Toconao, quienes se pronuncian como los legitimados para explotar turísticamente los paisajes y los recursos de una tierra heredada por criterios de derecho indígena. Sin embargo, aquello no significa exorcizar al pueblo de rutas turísticas, pues la localidad sigue siendo un sitio de paso y un punto de interés atractivo para el tráfico de pasajeros planificado desde San Pedro de Atacama.

Desde que Toconao es alcanzado por los circuitos turísticos, la condición de sitio de paso para las rutas sanpedrinas se siente inevitable. Algunos lo asumen con resignación y otros aprovechan con entusiasmo los tránsitos humanos movidos por la actividad. Estos primeros esfuerzos de sumarse al comercio para los viajeros comienzan con la importación de artefactos con estética andina, producidos en conocidos centros distribuidores del Perú y Bolivia. Esta tendencia de los sistemas turísticos, documentada por Escalona (2016), convierte a las poblaciones receptoras en comerciantes antes que productores, aunque también suele ocurrir que la situación se invierta hacia la producción. Poco a poco, los toconares 
aprovecharían la tendencia de los consumidores a demandar experiencias cargadas de exotismo, diversidad cultural y apreciación paisajística (Fuller, 2008).

Este vuelco paulatino de la población toconar hacia la producción turística no llega sino hasta los primeros años de la década de 2000, época caracterizada por la celebración de los contratos de asociación entre las comunidades atacameñas y la Corporación Nacional Forestal (CONAF) para la coadministración de la Reserva Nacional Los Flamencos. En este contrato asociativo, el papel de la Comunidad de Toconao es la conservación y la administración turística del sector Soncor y Laguna de Chaxa. Estos hechos, junto a una postura firme de la organización atacameña sobre los holdings trasnacionales, decantan en que la localidad asuma un mayor resguardo del patrimonio natural y cultural, a la vez que admite al turismo en su vida diaria:

[...] una medida es para controlar y poder proteger lo que tenemos, porque si nosotros dejamos entrar al turismo masivo nos va pasar lo mismo que en San Pedro de Atacama. Entonces lo que estamos haciendo como asociación es tratar de resguardar y de organizar a la gente para que se crea el cuento de que ya el turista llegó, vino para quedarse y no podemos hacerle un párale. Pero lo que sí podemos hacer es que nuestra gente trabaje con nuestros productos. Nosotros hemos estado incentivando a las personas a que no vendan sus terrenos, porque eso es lo que pasó en San Pedro de Atacama. Lamentablemente toda la gente fue vendiendo sus terrenos, la misma gente de San Pedro se fue replegando hacia los ayllus. Ahora San Pedro de Atacama está totalmente saturado, invadido de muchas culturas, y nosotros no queremos que pase esto con nuestro pueblo de Toconao, ni ojalá los pueblos más chicos. Queremos protegerlo, resguardar nuestras costumbres, nuestras tradiciones (Z. Minette, comunicación personal, 5 diciembre 2017).
El sistema turístico de la cuenca se asienta en una segregación de la población atacameña, cuestión que todavía se arrastra en los espacios de mayor beneficio económico del rubro, aunque con el tiempo se han abierto hendiduras donde es posible el emprendimiento indígena. En el testimonio recién citado se aprecian rasgos de política comunitaria que rechazan la posibilidad de replicar la experiencia sanpedrina. Tanto es así que dicha convicción tiñe casi la totalidad de las iniciativas turísticas toconares. Aunque abrirse al turismo parece contradictorio con el mencionado ostracismo, internamente la contradicción se repara tomando la actividad como una oportunidad de perpetuar la tradición.

En este proceso concatenado de contradicciones, los productos originarios del valle de Toconao y las propuestas que incitan su reproducción adquieren distinta magnitud y visibilidad dentro del catálogo turístico de la cuenca, aunque con constante cuidado de no perderse en la masividad. Lo cierto es que el rubro turístico ofrece algunas oportunidades de desarrollo local, cuestión que en Toconao es vista como obtención de un ingreso más o menos estable y una fuente laboral necesaria para mantener actividades prediales productivas, las que a comienzos de siglo amenazaban con desprenderse de la economía toconar (Núñez, 2002). En esta revitalización se repara la aparente oposición entre el ostracismo y la apertura, lo que en ningún caso quiere decir que se valore positivamente la experiencia sanpedrina.

En resumidas cuentas, la situación de San Pedro de Atacama resulta traumática en la memoria reciente de los toconares y a partir de ella han establecido lineamientos políticos y económicos básicos para actuar en el rubro turístico. Entre ellos resaltan el imperativo de 
trabajar con productos locales, incentivar el trabajo vecinal y pertenecer a la etnia lickanantay. Desde este punto de partida, la actual década que está pronta a terminar estuvo protagonizada por los emprendimientos indígenas que recogen dichos principios y que se enfrentan a la tensión entre el ostracismo proteccionista y la búsqueda de protagonismo en la economía del turismo.

Con el vino de altura de Toconao se expresan varias de las ambivalencias traídas a colación, entre ellas la inversión turística y la protección, el hermetismo contra la apertura y la tradición y la proyección a futuro. Estas dinámicas son las que llevan a preguntarse cómo se construyen nuevas narrativas sobre la etnicidad en el escenario turístico, cuestión inteligible al dar cuenta de sus procesos (Bustos, 2015). Con este convencimiento, la vinicultura de oasis se muestra como un asunto constructivo, donde confluyen diversas fuerzas externas, la política comunitaria y la inventiva indígena, lo cual posibilita la actual mercantilización de la actividad predial del pueblo pétreo.

\section{Vinos de altura en el salar de Atacama}

La tradición etílica toconar está lejos de ser una elucubración aparecida en situaciones turísticas en cuanto sus fuentes se remontan al primer siglo de conquista española, época en que los europeos narraron la permanencia de tinajas para la fermentación de chichas de chañar y algarrobo en los hogares de los nativos (Téllez \& Silva, 1989). Sin embargo, a poco de iniciada la campaña colonialista en Atacama los conquistadores llevan a cabo obras de sustitución de cultivos por injertos frutales traídos del Viejo Mundo (ídem). Con el tiempo, las plantas frutales se adaptaron al microclima de oasis en altura y adquirieron la denominación de ecotipos locales, o sea, varietales acomodados al ambiente desértico en altura que después de siglos han tomado formas específicas.

Uno de los injertos frutales que data de la historia colonial del oasis es la Vitis vinifera, planta trepadora que brinda uvas de mesa y para vinificación, en cuya plantación los conquistadores españoles insistían por su papel central en el culto católico. La tradición vinícola lickanantay es asociada desde su raíz a la religiosidad, tanto así que el consumo de bebidas alcohólicas es declarado como parte de la cotidianeidad y la ritualidad tanto de los abuelos como de los actuales atacameños. Es así como los pueblos del salar mantienen ciertos lazos entre la espiritualidad y la ingesta de licores, mismos que se aprecian en las procesiones del culto mariano, que culminan en un festín de patasca y vino tinto, y en la concesión de favores al Mallku (cerro tutelar) y a la tierra, cuando las bebidas son convidadas a las entidades naturales:

Es que está el vino, que en este caso se hace porque en ciertas ocasiones pagas está inserto en lo que es la ritualidad, en pago en ofrendas a la Madre Tierra, al agua, a los cerros, a las deidades y es parte de esta forma de vida. Ahora también hay que reconocer, y esta parte guárdala, aquí hay una fuerte cultura etílica, entonces esto también va en tu forma de vida, en tu enseñanza (M. Silvestre, comunicación personal, 5 diciembre 2017).

El origen del vino de Toconao, asociado a la evangelización de los nativos en el catolicismo, encuentra su cuna en el valle de Jere, una quebrada fértil hacia la ladera este del poblado, que por hoy es tanto circuito de senderismo y zona de picnic como reserva de huertas 
familiares. Los orígenes eclesiásticos de la vid se establecen en que "los monjes vienen con las parritas para hacer el vino para la misa, para el sacramento. Estos viejos encontraron que Jere era un bonito lugar y con las características de suelo, agua y clima para producir parras" (S. Marchant, comunicación personal, 1 diciembre 2017). Localmente, la cepa país y moscatel de Alejandría son reconocidas como las variedades originarias de la vitivinicultura del oasis atacameño, con las cuales se prepara el antiguo vino de misa o criollo. En algún punto impreciso, los vinos se toman los lugares ceremoniales, disminuyendo la importancia ritual y cultural que otrora tuvieron las chichas del chañar o algarrobo (Martínez, 1998).

Actualmente, los licores no satisfacen tan solo inquietudes religiosas, ni tampoco todo el consumo toconar corresponde a producción local, pues desde la conexión de Toconao con la carretera Panamericana desde la década de 1960 ingresan productos importados a bajo costo (Comisión Verdad Histórica y Nuevo Trato, 2003). A raíz de la conectividad del pueblo, los toconares se acostumbran a las cervezas, los vinos y los destilados de distribución nacional, lo que no quiere decir que la manufactura alcohólica local decaiga completamente. Aún persiste la producción localista de bebidas alcohólicas en dos grandes familias de vinos: uno antiguo y heredero de técnicas artesanales, el criollo, y otro más reciente, fabricado con procesos tecnificados, el Ayllu.

Los toconares declaran que la técnica de vinificación del criollo es herencia de las formas de los abuelos, quienes durante centurias habrían practicado el tratamiento de la vid bajo las condiciones microclimáticas de oasis. Un proceso minucioso que requiere del arte de la paciencia y que parte con el filtrado de los mostos por medio de un zarzo, es decir, un tejido de cañas. Los mostos y parte de la borra son fermentados en un cántaro o vilque, tradicionalmente de greda, aunque por estos días se utilizan botellas de vidrio y alambiques. El vino nonato comienza su fermentación alcohólica en ausencia de aire. Para conseguirlo los viñateros son cuidadosos en almacenar en hermetismo, recurriendo al guardado de la bebida bajo tierra, o al menos así se hacía originalmente.

La producción de vino criollo corresponde a una manufactura casera, guardada por ciertas familias toconares y viñateros distinguidos, los cuales son reconocidos como artistas talentosos dentro de la comunidad. La bebida artesanal circula principalmente entre vecinos y parientes, se reparte en carnavales y ceremonias, o en ocasiones es convidada a algún viajero que logre caer en gracia. Sin embargo, con el reciente packing del Ayllu, el poblado cuenta con un stock importante de botellas de vidrio, que también se utilizan para envasar el vino de misa. Con el embotellamiento, y ahora etiquetado, es posible la comercialización del vino dulce en el tráfico de visitantes, aunque no es la tendencia más popular entre sus productores, quienes prefieren que continúe distribuyéndose entre conocidos o pasando el dato de "boca a boca".

El vino criollo deriva de la agricultura tradicional de Toconao, o sea, policultivos frutales en espacios prediales relativamente reducidos, los cuales son regados por inundación con un antiguo mecanismo de terrazas en suave pendiente (Villagrán, et al., 1998). El sistema de huertas interconectadas por canales facilita el aprovechamiento óptimo del recurso hídrico, que tiende a escasear en la hiperaridez. La fruticultura múltiple encierra 
variedades de especies vegetales en melgas dispuestas de forma escalonada para aprovechar el curso acuífero. Es común que estas plantas y árboles compartan el espacio con algunas parras de uvas rechonchas y dulces. Para los toconares estas técnicas y modos de producir son patrimonio vivo de los oasis andinos, una costumbre arraigada por la tradición y de innegable efectividad, aunque los procesos del vino nuevo traen una técnica que generaría resistencia entre gran parte de los viñateros y los agricultores.

Esta que llamaremos la segunda oleada de vitivinicultura toconar encuentra su origen en la década de 2010, años en que ocurre una serie de acontecimientos que resultan en la organización de algunos comuneros bajo una figura de cooperativa avocada al rubro vitivinícola. El funcionamiento mediante cooperativa es un asunto escaso en la actual industria viñatera chilena, ya que de acuerdo con Del Pozo (2014) la tendencia de esta forma asociativa va en declive, pues el grueso de ellas se ha agrupado en sociedades anónimas, ha cedido sus derechos a oligopolios o se ha volcado a la producción frutal. Es notable el hecho de que en Toconao se impulse una estrategia de trabajo y negocios casi abandonada en el mercado del vino nacional, sobre todo considerando los tintes étnicos de la organización que asume el nombre de Cooperativa de Viñateros de Altura Lickanantay.

La organización de la cooperativa surge primero de necesidades de fomento agrícola, una actividad que hace poco había sufrido un golpe severo por los aluviones del invierno altiplánico, es decir, ciclos lluviosos que interrumpen las temporadas estivales causando estragos en la producción predial en general. Comenzando el decenio de 2010, los aludes ocasionaron repentinos aumentos de las corrientes endorreicas y arrastraron huertas de propiedad toconar ubicadas en el sector Jere, llevando consigo frutales, parras e incluso terrazas. La serie de aluviones resultó ser un desincentivo agrícola que caló profundo en la retina de los comuneros, sobre todo considerando que las "venidas" golpearon fuerte a esta economía primaria hace rato en declive:

Fue el 2009, después de que empezaron una serie de aluviones, empezaron a subir muchos los caudales y nos dimos cuenta de que con el primer aluvión grande perdimos huertos. En ese tiempo me tocó ser dirigente de la Asociación de Agricultores [...], comencé a decir que estábamos decadentes, básicamente con el mismo discurso. $Y$ comenzamos a hacer una serie de reuniones, juntamos a todas las asociaciones agrícolas de Toconao. [...] En ese momento SQM dijo como: "parece que estos locos están llegando a algo". Y mandó a Jaime Contesse, el hermano de Patricio Contesse. Un viejito rechoro, que vino para acá y analizó qué cosa se podía hacer, qué negocio se podía ver. Yo le hice un circuito, una visita para todos lados. El viejo se llevó tres botellas de vino y ahí partió la cuestión, y dijo: "la cuestión es el vino". Ahí partió el programa Atacama Tierra Fértil (S. Marchant, comunicación personal, 1 diciembre 2017).

El programa Atacama Tierra Fértil (ATF) resulta un ejemplo de las medidas de mitigación tomadas por las empresas extractivas para reducir las condiciones de vulnerabilidad de las comunidades afectadas por su actividad. Tales industrias están obligadas a recurrir a políticas de buen vecino con las localidades, cumpliendo así la Declaración de Río de Janeiro de 1992 (Bolados, 2014). En ese marco, ante la destrucción de predios por acción del aluvión, la empresa SQM estableció medidas de asistencia y fomento agrícola como una forma indirecta de reparación por los conflictos suscitados entre la comunidad y la minera no metálica por la extracción acuífera en el salar de Atacama o la ocupación de terrenos ancestrales. 
La implementación del programa ATF comienza entre los años 2010 y 2012 con la intervención sobre ciertos parajes prediales del valle de Toconao con el fin de instalar mecanismos de riego tecnificado por goteo. La conversión del espacio a la fecha es evidente considerando que antes de la adopción de procesos técnicos los toconares contaban con alrededor de 1.600 parras repartidas en varias huertas, mientras que la cosecha de 2018 contó con más de 16.000 plantas de uvas de diversas cepas. El fomento agrícola se concentra en el sector sur del poblado, denominado Campo, sitio en que los comuneros llevaban una agricultura escalonada en terrazas, donde los frutales de raíz profunda eran idóneamente regados por inundación. Esta técnica tradicional de agricultura de oasis es modificada por el programa de la minera, quienes incitan a los suscribientes a reemplazar los policultivos por hileras de Vitis vinifera.

La adopción de terrenos con monocultivo de Vitis vinifera implicó cambiar las formas de riego dado el manejo delicado que requiere la planta y la alta demanda de agua de las parras, las cuales precisan un mínimo de 4 litros por cada dos días. La exhortación del programa ATF encontró resistencias entre varios comuneros, quienes no estaban dispuestos a transformar sus heredades por una empresa que aún no era segura. En ningún caso, el fomento agrícola implicó aumentar las cuotas de agua de los comuneros, sino modificar el uso que se hace del recurso. Por eso se buscaba implementar un sistema de regadío capaz de aprovechar los acueductos ya instalados hace tiempo en el oasis. A pesar de las tensiones entre los productores agrícolas al implementar el programa de la minera, a comienzos de la década de 2010 se consolida la instalación de terruños con riego tecnificado.
El nuevo sistema tecnificado de riego consiste en dirigir los canales de regadío hacia tranques medianos o piscinas, las cuales se bombean con motores impulsados por paneles fotovoltaicos. El uso de la energía solar en la maquinaria regante de alguna forma se convertiría en parte del discurso detrás de la mercancía vinícola, pues la sustentabilidad formaría parte de las bondades del vino joven. Los terruños del sector se conectan con las fuentes hídricas a través de un mecanismo de tuberías, las cuales reparten el agua por goteo para el riego pausado de las parras. Con este sistema, la cooperativa lleva los últimos cuatro periodos produciendo anualmente 7.000 litros de vino seco, es decir, más de 9.000 botellas de la marca Ayllu.

Al determinar la marca de vinos Ayllu se despliega una serie de estrategias de mercadotecnia para posicionar el producto en el tráfico turístico y gastronómico ya establecido en la cuenca del salar de Atacama. Para ello los viñeteros recurren a la valoración de antiguas costumbres locales para resignificarlas en contextos mediados por la comercialización de experiencias y productos endémicos: específicamente se renuevan las antiguas vendimias del oasis de Toconao. Esta actividad era motivo hace cuatro décadas de trabajo y fiesta comunitaria, una celebración basada en relaciones de reciprocidad vecinal, las cuales han perdido ese carácter por el decaimiento sostenido de la actividad agrícola. Aun así, en los recovecos de la memoria local se exalta esta actividad, presa de la nostalgia y el desuso, pero ahora con una función distinta a la que tuvo antaño:

[...] pasó que yo ya hacía vino, mis abuelos, mis padres ya hacían vino en la quebrada Jere, pero acá en el Campo era muy poca producción por el tema del riego, que era un riego por inundación antes. Ya el 2011 se hace la primera plantación que tengo aquí, la 
de syrah, y el 2012 malbec, petit verdot y chardonnay [...] Bueno, las vendimias empezaron cuando ya teníamos un stock de vino, vino seco. Antes se hacían de cierta forma, pero no eran eventos. Ahora son eventos en la plaza, donde apoya el programa Atacama Tierra Fértil para traer conjuntos, para cerrar todo, para hacer stand, todo el tema. Entonces se le da una buena promoción al vino. $Y$ ahí hay un punto fuerte, en realidad para todos los otros agricultores que no tienen ruta del vino, que no tienen cómo posicionarlo. Entonces ahí aprovechan de venderlo (W. Cruz, comunicación personal, 1 diciembre 2017).

Los adultos toconares cargan en la memoria hitos pasados basados en jolgorios y trabajo duro relacionado con el vino dulce, cuestión relacionada con multiplicidad de recuerdos de Toconao como pueblo eminentemente frutícola. Esta historia los encasilló mucho tiempo como parte de la red minera del Norte Grande durante buena parte del siglo $\mathrm{XX}$, ya que era común que los productores toconares abastecieran los campamentos mineros de la época con sacos de fruta, tiempos recordados como la época dorada de la agricultura de oasis. Del mismo modo, la tradición vinícola es relatada con anecdótica poesía, como un asunto comunitario donde se desplegaban lazos vecinales para extraer la uva de la quebrada de Jere, donde el trabajo se repartía colaborativamente, pues llegada la vendimia a cada voluntarioso le tocaba una parte del vino dulce acabado por sus artesanos.

En esta década, las vendimias adquieren otra connotación, ya que al reactivarlas se difunde en la región como un resurgimiento que apela a la memoria, vinculando el evento con tradiciones prediales que han cambiado con el paso del tiempo a otras formas de trabajo y consumo. En el año 2014 se consolida una producción más estable, que supera las 1.500 unidades ofrecidas al mercado en el debut de la marca. Contando con una cantidad suficiente de vino seco, se celebran nuevos periodos de cosecha auspiciados por el programa ATF, donde la atención se dirige a las degustaciones de los colores y las cepas del vino, acompañamiento de maridajes y platos típicamente atacameños, todo al son de música andina y estilización con motivos que homologan la indianidad desértica. Con un cobro de entrada asociado, se invita al turista y al afuerino a participar de la actividad y llevarse una botella del Ayllu bajo el brazo.

Los eventos viñateros no han cesado de celebrarse desde su renovación, con lo cual han adquirido una visibilidad creciente entre las experiencias turísticas comunales. A nivel local el interés por aprovechar el trampolín de ventas que significa el evento recibe una sucesiva atención y adhesión. De esta forma, otros productores no asociados a la cooperativa aprovechan el tráfico de invitados y visitantes para ofertar mercancías artesanales, ya sea vino dulce, esculturas en roca volcánica ${ }^{4}$ y otras manufacturas con base en ecotipos locales. Aunque la incorporación de otros productores locales a las mesas de la vendimia ha suscitado un beneficio creciente, la iniciativa no está libre de críticas, varias de ellas basadas en que el programa ATF benefició solo a cierto grupo de agricultores.

Con todo, la cooperativa viñatera ha sacado durante los últimos años cuentas alegres de la venta de botellas al público durante la instancia de la vendimia, ya que resulta un primer punto de ventas seguro para obtener ganancias de la producción anual. Pero un solo día al año no agota las existencias de vino seco, por lo que se abierto otros canales de comercialización distintos al evento, todos relacionados directamente con el tráfico turístico. Aquí influyen aspectos de política comunitaria que se toman con serio determinismo el posicionamiento de producción endémica en el mercado turístico. 
Así, la organización comunitaria sobre turismo, Saire Haalar, lleva más de diez años buscando el desarrollo poblacional en esta actividad. Con ese objetivo claro asesoran iniciativas de artesanos y fabricantes locales para posicionar objetos y trabajos en las tiendas y las ferias de comercio exclusivo lickanantay.

La puesta en venta del vino seco también fluctúa en estos puntos de comercio exclusivo, sobre todo en aquellas tiendas abiertas al turista donde se ofrece una serie de manufacturas toconares vendidas como enseres exclusivos del oasis, entre los cuales una botella de Ayllu alcanza los 15.000 CLP. Claramente, los precios del Ayllu se ajustan al nivel de consumo de los visitantes, a quienes está dirigido el producto, quienes generalmente son buscadores empedernidos de viñas alternativas y orgánicas, "gringos" viajeros, afuerinos de paso y enólogos tanto profesionales como amateurs. Casi todos estos personajes convergen en otro punto de distribución, uno que figura como empresa y que concentra gran parte de la producción viñatera local, el complejo turístico El Toconar, una figura donde se hace mucho más evidente la conversión de las actividades agrarias en propuesta turística.

El Toconar es una empresa local abierta a distintos giros comerciales aparte del rubro turístico, entre ellos un mini mercado en el centro del poblado, producción agrícola, sobre todo frutal, un par de restaurantes en San Pedro de Atacama y, de más está decir, la vitivinicultura. La apertura hacia el comercio del vino, en este caso, se da con la participación de su cabecilla en la cooperativa viñatera, donde actúa como dirigente, aunque a diferencia de la mayoría de los productores, él despliega una cuantiosa inversión privada dado el capital más aventajado que detenta. Las extensiones pecuniarias personales y las operaciones del programa de SQM decantan en que la ya existente explanada hotelera potencie su atractivo con la Viña Santa Romina como punto de interés visitable.

Figura 1: Turistas en Viña Santa Romina, diciembre de 2017. Fotografía propia.

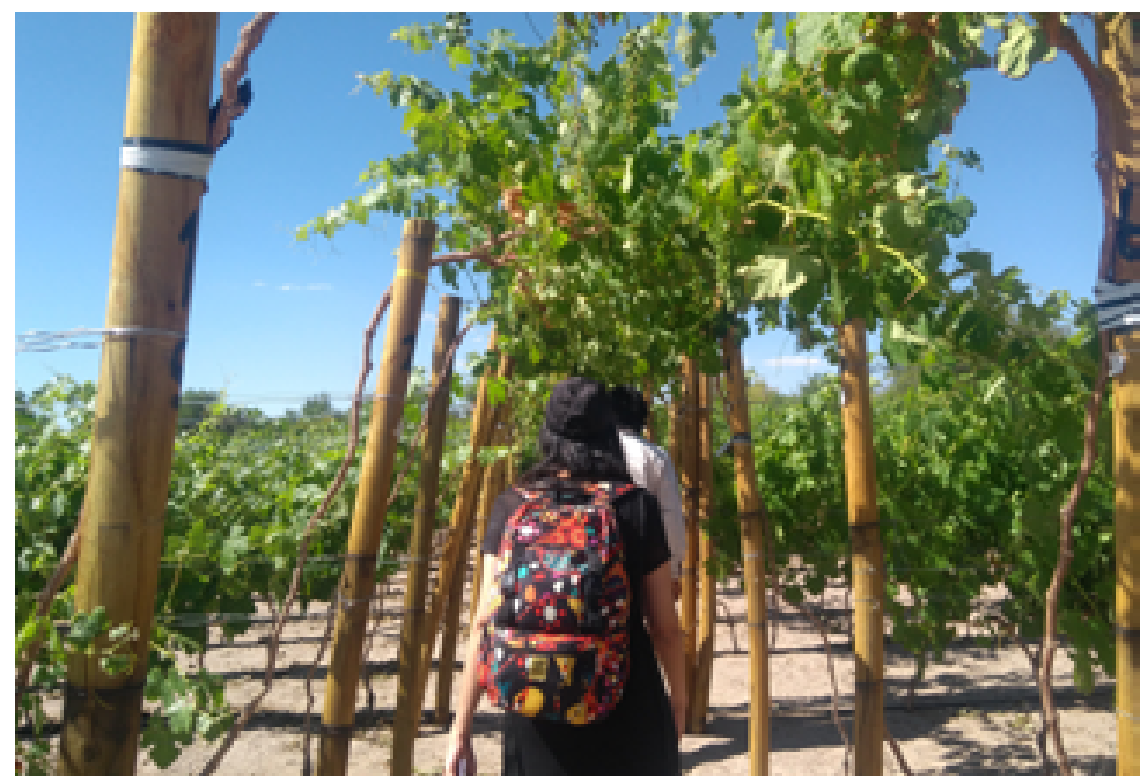


La Viña Santa Romina (Figura 1) es un terruño que se extiende por tres cuartos de hectárea, cuestión no menor considerando que la totalidad de los terrenos cultivables del valle de Toconao no cubren más de 43 ha (previo al aluvión de 2012 eran 60 ha), en las que se reparten la actividad frutícola y agroganadera en general. Al igual que los otros vinicultores, la heredad es ocupada exclusivamente por la Vitis vinifera, aunque mantiene reductos de huertas para consumo familiar y abastecimiento del almacén propiedad de la empresa. De los 7.000 litros de vino elaborados por la cooperativa local, solo las parras de El Toconar son responsables de alrededor de 2.500 litros al año, lo que lo establece como el mayor productor vinícola del valle desértico del Norte Grande.

La amplitud de terrenos y la instalación hotelera conjunta a la Viña Santa Romina permiten hacer de esta una experiencia apetecible para consumidores de vinos y nuevos peregrinos, promovida también en páginas web y entre agencias turísticas. Las rutas del vino han encajado en un rubro turístico en constante búsqueda de diversificar propuestas para captar distintos públicos para viajes y lugares (Gundermann, 2004). Por otro lado, los trotamundos contemporáneos se caracterizan por cargar consigo discursos de conciencia ecológica y diversidad cultural, aspectos concretizados en tipos especiales de turismo (Fuller, 2008), los cuales se ven satisfechos en la invitación de El Toconar a las visitas enológicas guiadas por el valle de Toconao, autodeclarado heredero de una vinicultura de oasis en altura.

Las visitas guiadas a los terruños toconares son dirigidas por guías locales, contratados y capacitados por el complejo hotelero, quienes bajo la figura laboral de trabajo a medio tiempo perciben ingresos complementarios a su actividad agrícola o empleos asalariados un tanto más permanentes. Estos interlocutores entre el turista y la viña depositan en sí mismos el papel de anfitrión, personaje que conduce a los visitantes a través de senderos rodeados por parras. Se encargan de enseñar la complejidad del tratamiento de la vid en condiciones de estrés ambiental desértico, sin dejar de lado la historia agrícola heredada por los abuelos lickanantay. Esta performática turística se adorna con habilidades discursivas que mezclan los aspectos objetivables del vino con la tradición que se supone encierra cada botella. 
Figura 2: Cata del vino Ayllu, diciembre de 2017. Fotografía propia.

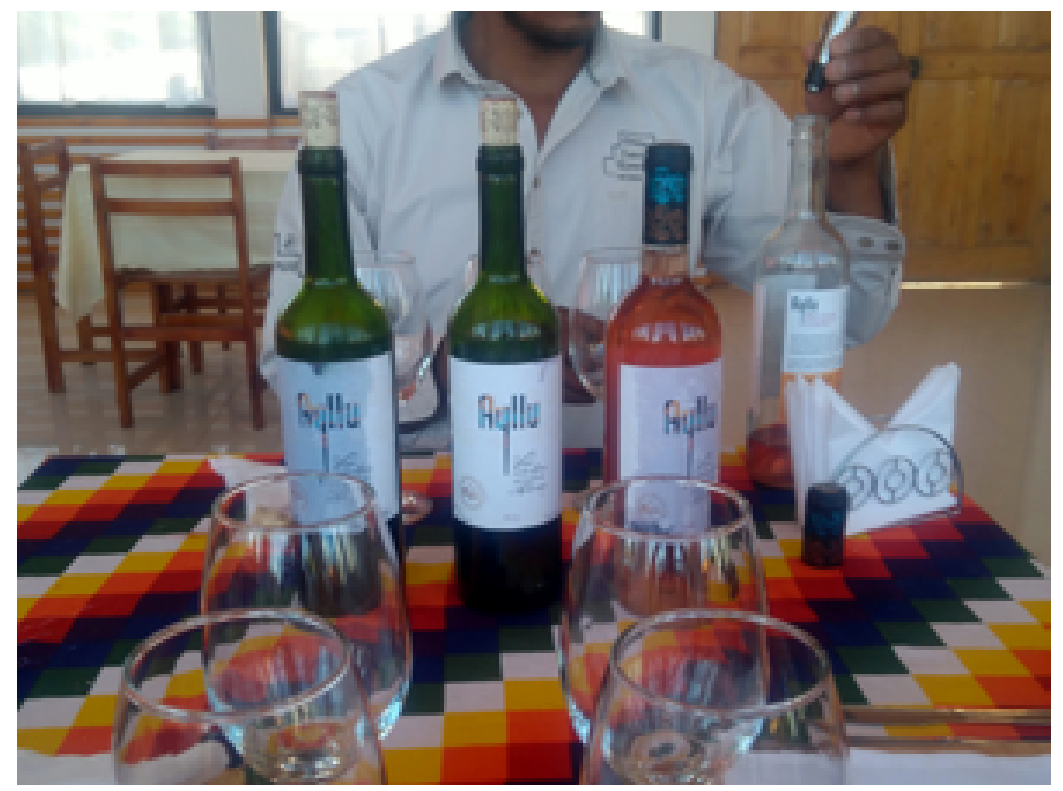

La visita guiada a los terruños toconares termina en una cata guiada de vinos con un maridaje (Figura 2), el cual enaltece las cualidades descriptibles de la bebida, que en términos de jerga enológica se refieren a los terroir del vino, es decir, la expresión de las características del suelo en la bebida. Aquí resalta el estrés ambiental por la altura y el ambiente hiperárido donde germinó la parra, las notas frutosas de la agricultura de oasis, el fuerte componente mineral que dota de sensación de sequedad, etc. Así la narrativa enológica del valle de Toconao teje un discurso que reúne los aspectos del microclima de oasis como un sitio privilegiado para la vinicultura, a causa de sus tierras fértiles de origen volcánico y agua en estado puro.

Todas estas características del producto son reproducibles por sí solas en la diversificada vinoteca chilena, sin embargo, es poco lo que el vino Ayllu se aventura fuera de la cuenca del salar de Atacama y encuentra un destino más claro entre consumidores de turismo. Con el nivel de concurrencia de viajeros en la región, los potenciales compradores de la mercancía vinícola no son pocos y tanto es así que el stock mayoritario detentado por El Toconar no da abasto en las temporadas altas del turismo. Pero las rutas del vino resultan bien lucrativas y agregan una experiencia exótica e inesperada a los visitantes del complejo, por lo que su dueño compra unidades de vino a otros miembros de la cooperativa con una producción más baja y sin plataforma de ventas estable.

Las características adosadas a los vinos de la marca Ayllu circulan en un mercado donde los consumidores pueden acceder a un "producto de una perspectiva cultural específica, resultado del trabajo que se supone implica un conocimiento especializado y que expresa formas de entendimiento del mundo que son también específicas de un grupo social" (Escalona, 2016, p. 261). En 
el caso de los viñateros lickanantay, la expresión de alteridad en el mercado no solo atañe a los rasgos indígenas, pues en la dotación de significados se le invocan al vino aspectos históricos con un sentido fuertemente local.

En la promoción de la mercancía vinícola del oasis se expresa una labor rescatista del poblado atacameño, que busca prácticas y objetos en su propia herencia cultural, esforzándose con determinación por aprehender los aspectos del pasado y proyectarlos en el turismo con una imagen de autenticidad. Dicha proyección turística no es separable de la tradición rememorada, pues ambos aspectos se fusionan en una estrategia política y comunitaria con efectos en la vida productiva y cotidiana de los poblados indígenas (Álvarez, 2018). De esta forma, la organización toconar busca intensificar su sello de diferencia como localidad y como grupo portador de costumbres específicas. No es que nieguen su indianidad sino que exploran otras identidades que actúan en conjunto con ella.

La empresa turística de Toconao cuenta con una historia relativamente breve, pronta recién a cumplir una década. Durante este periodo, los viñateros lickanantay han demostrado ser estrategas efectivos al no fundirse en la masificación sanpedrina y generar nichos de desarrollo económico. Por esta condición, los vinos del oasis conciernen cada vez a más actores interesados en sus servicios complementarios o directamente en la producción vinícola. Tomando esto en cuenta, incluso algunos viñateros artesanales han sumado el vino dulce al abanico de mercaderías toconares y junto a ellos un contingente de artesanos y productores frutales se esfuerzan por reproducir sus artes en la producción turística.
Por su parte, la cooperativa ha dotado paulatinamente a sus procesos de estandarización y especialización en materia vinícola y comercial. Tomar este curso de acción implica una capacitación constante en asuntos técnicos y conocimiento especializado en temas de vinificación. Bajo este parámetro, el enoturismo del valle de Toconao y la correlativa puesta en valor del insumo vinícola exigen a sus productores una creciente destreza en mercadotecnia y producción para competir en un mercado comunal heterogéneo y diversificado, donde siempre es posible evaporarse en la invisibilidad.

La estandarización de la producción de la Cooperativa de Viñateros de Altura Lickanantay es fundamental para crear una marca asociada al nombre Ayllu. Para conseguir este objetivo, el programa ATF implica también implementar una serie de procesos técnicos de vinificación, ya completamente alejados de las formas artesanales de los abuelos. En las bodegas otorgadas por la empresa minera, los viñateros lickanantay exploran formas innovadoras de atraer compradores y visitantes a su propuesta enoturística, indagación que aplica métodos difundidos en la vinificación contemporánea, tales como el añejado en barricas de roble francés o la mezcla de varietales para elaboración de vinos de corte o ensamblajes.

Desde que debuta como un vino joven en 2013, el vino Ayllu ha estado en el centro de la experimentación con múltiples cepas plantadas en las tierras del oasis y cuenta hoy con distintos injertos de varietales franceses ${ }^{5}$. La vinificación ahora se dirige a la adopción de técnicas que van dejando atrás el ensayo y la prueba para dar paso a un producto estandarizado y con identidad. Si bien este perfeccionamiento apunta a la familia de vinos secos, con la vitalización de 
las vendimias también el vino dulce ha avivado un interés sin precedentes entre enólogos y el periodismo viñatero. Asimismo, los productores y consumidores de estos vinos familiares lo están defendiendo con encendida pasión como algo auténtico, realmente artesanal o, cuanto menos, como algo exclusivo:

Aquí cuando hacen esto de la vendimia, la gente igual vende su vino criollo y no es competencia. Ahí tienes diversificación del mercado de vinos y hay más a quienes venderles, a quienes le gustan los vinos amargos o los vinos dulces. A los que les gusten más los vinos con cuerpo, con otros aromas, le apuntarán al Ayllu, para un tipo de carnes, un tipo de ocasión. El otro es para un amigo, como un amigo que no ves hace años $y$ sentarte a conversar. $\mathrm{O}$ es un buen regalo de algo artesanal que no lo tiene cualquiera (M. Silvestre, comunicación personal, 5 diciembre 2017).

La especialización viñatera y su mercantilización condensan una serie de hechos históricos que llevaron a los toconares a innovar en el escenario turístico, donde la diferencia cultural es demandada por consumidores y agencias afuerinas. Con el proceso de turistificación de la vitivinicultura de oasis, se expresa una tendencia a la incorporación de tradiciones específicas a la economía del turismo. Se trata de una forma de darle actualidad a narrativas pasadas, como también una manera de movilizar recursos naturales disponibles en los predios del poblado. Los pobladores ven en esta remembranza cierta continuidad histórica de localismo e indianidad, con la que sostienen la autenticidad de sus propuestas:

El local es el llamado a abrir las puertas de la casa, tú tienes que ser cien por ciento la persona que tiene que atender, recibir y vender. Es importantísimo porque es tu tierra, eres tú el que vive acá. Entonces, el ser indígena te da un doble papel, que es un valor agregado a tu producto que vas a vender. O sea, si vas a visitar un pueblo que te atienda mejor el dueño de casa, me gustaría entablar una conversación con un indígena, conocer directamente a la persona que vive ahí (J. Cruz, comunicación personal, 18 enero 2019).

La capacidad de brindar valores agregados a la producción local a través de la proyección de etnicidad es algo manifestado de forma lúcida entre los toconares. Con este ejercicio consciente de atribución de significados, los pobladores lickanantay se toman cada vez más en serio su papel en el turismo, ya no como algo que solo ocurre sino como un espacio donde se disputan protagonismo. La producción deliberada de etnomercancías y su especialización empuja al debate sobre los usos de la etnicidad en el turismo, cosa que no es solo simbólica ya que implica cómo se plantea la economía y la política de los comuneros indígenas. Aunque la inventiva local puede desarrollar esto de formas inesperadas, se observa en Toconao una tendencia hacia el funcionamiento corporativo, lo que lleva a revisar riesgos y posibilidades.

\section{Los empresarios lickanantay}

Desde el asentamiento del turismo en la comuna de San Pedro de Atacama en los noventa, la posibilidad de obtener beneficios de la actividad ha dependido principalmente de la capacidad de inversión inicial (Gundermann, 2004), razón suficiente para que las poblaciones oriundas fuesen marginadas desde un principio. Pero tal como se ha expuesto, con el tiempo algunos segmentos de esta población adquirieron poder adquisitivo y tierras suficientes para invertir en iniciativas turísticas como propietarios o emprendedores. En varias ocasiones, estos inversores indígenas también ocupan dirigencias locales, con lo que se forma una figura difusa entre el empresario y el líder 
comunitario, cuestión que establece formas particulares de competir por la renta turística.

Como se ha visto, el turismo representa una entidad trasnacional que va más allá de lo económico, pues se alza como un paradigma de cambios en la vida cotidiana de las comunidades implicadas (Bolados, 2014). Cuando las localidades se vuelven parte de programas turísticos existen riesgos asociados. La literatura reconoce que en varios casos las poblaciones se vuelven museos al aire libre y áreas de diversión pasajera, donde el medio físico se deteriora y los vecinos son paulatinamente expulsados (Fuller, 2008). En la cuenca del salar esto coincide con la experiencia sanpedrina, cuestión que ha llevado a los toconares a adscribir a áreas específicas de la industria menos invasivas y con mayor protagonismo.

El fuerte componente localista se deja notar en todas las iniciativas turísticas toconares. Al hacerlo así se protegen de la temida invasión afuerina, pero al mismo tiempo levantan un modelo de negocios particular. Este modelo es comprensible bajo las figuras de etno y ecoturismo, donde el primero tiene como principal atractivo una identidad particular y comercializa con productos y experiencias igualmente singulares; el otro apunta a la planificación sostenible del patrimonio natural y cultural (Fuller, 2008). La explotación creciente de dichas características implica tanto que la comunidad articule sus recursos económicos y culturales a las expectativas de agencias y viajeros, como que fije lineamientos de política interna en el proceso (Álvarez, 2018).

Al incorporar un amplio espectro de la vida comunitaria en el turismo, este adquiere un papel central en el desarrollo y la cotidianeidad del grupo, estableciéndose como una industria cultural que moviliza imaginarios y discursos en pos de la propiedad patrimonial (Álvarez, 2018). Es un proceso no exento de tensiones, en el que emergen pequeñas empresas o emprendedores entre los comuneros indígenas, quienes "pretenden compensar las necesidades de falta de empleo entre la población, estas iniciativas se han logrado con la alianza política entre pequeños empresarios y representantes del sector gubernamental" (íbid., p. 90).

Para el caso toconar, la aparición de empresas $\mathrm{u}$ otras figuras corporativas es incipiente, pero ya son visibles varios de los aspectos descritos. Se agrega también que su formación responde a necesidades coyunturales. Son varios los aspectos reivindicativos en la base de la empresa étnica, entre los cuales se observan factores políticos, ambientales y el refuerzo etnogenético. Estas estrategias son invocadas frecuentemente por grupos étnicos para debatir asuntos de desigualdad histórica (Castillo, et al., 2017). Más allá de estos tres componentes, esta forma empresarial no dista de cualquier sociedad comercial, a pesar de que muchas veces no sea tratada como tal a causa de la imagen primordialista creada en torno al ser indígena (Álvarez, 2018).

La empresa étnica toconar encuentra una relación con las dirigencias locales en su naturaleza reivindicativa pues estos atributos suelen ser encarnados por líderes atacameños. Estos son sujetos capaces de movilizar procesos patrimonializadores y reivindicativos (Morales, 2016), es decir, que los personajes con peso político han sido los más capacitados para emprender o formar pequeñas empresas. Ello se debe, en gran medida, a la acumulación de capitales de ciertos comuneros, acompañados también de conocimientos técnicos, capacidad administrativa y especialización en la materia. 
Lo anterior se observa en distintos casos: el mayor productor viñatero de Toconao, lideraba a comienzos de este siglo las negociaciones con la CONAF para la recuperación de los salares de la Reserva Nacional Los Flamencos. Otro ex dirigente agrícola aprovechó los predios familiares y la especialización agrónoma para ofertar recorridos por la herencia frutícola de Toconao. También tienen una mención especial los guías turísticos de la reserva, quienes se han convertido en personajes políticamente activos y figuras respetadas dentro de la comunidad, aunque se trata de trabajadores dependientes sin inversión cuantiosa en turismo.

Es claro que los beneficios de la actividad turística no se reparten de forma equitativa, pues se establece una forma desigual de división del trabajo comunitario, donde los comuneros sin capacidad de inversión deben vender su fuerza de trabajo a la industria cultural (Comaroff \& Comaroff, 2009). Por otro lado, surgen nuevas formas de dependencia interétnica, pues la etnoempresa sigue dependiendo del sistema turístico, por lo que queda sujeta a los vaivenes de este mercado y la presencia de grandes holdings. Por lo tanto, si bien la localidad alcanza cierta autonomía en la participación de las ganancias del turismo, conocer las relaciones subalternas surgidas de ella será un terreno de investigación que queda abierto.

\section{Comentarios finales}

Con el paso de cada temporada turística en Toconao se van incorporando progresivamente emprendimientos locales que buscan una oportunidad de desarrollo por medio de las evocaciones de la tradición, reinventando y reforzando una identidad en contextos mediados por el mercado trasnacional de la cultura. El rescate de actividades prediales para turistificar responde, en parte, a la urgencia de encontrar un uso rentable para un sector primario que a comienzos de este siglo daba señales de una profunda decadencia. La remembranza apunta a objetivos claros, definidos por la política comunitaria: no replicar la experiencia sanpedrina, sino potenciar en el turismo los productos endémicos, fomentar el trabajo y rescatar tradiciones arraigadas en el oasis toconar.

El hecho de que la política del poblado defina lineamientos estratégicos para defender a Toconao de las lógicas turísticas trasnacionales al mismo tiempo que incentiva la inversión en la actividad revela una apertura del grupo lickanantay a las oportunidades de la industria cultural, con reservas, pero aun así con pujante interés y determinación. En esa línea, el fomento viñatero de la última década ha aprovechado este arranque para generar una producción "con identidad", que difiere de las técnicas artesanales, pero que se declara su heredera. Se aprecia una proyección de tradición en el vino seco de oasis, posibilitada por procesos de etnificación cada vez más explícitos entre las poblaciones de la cuenca del salar, pero también se suma una diáspora de narrativas identitarias, que se exploran y aprehenden entre los pasajes de la historia local.

La reciente reinvención de la tradición viñatera de Toconao sirve de vehículo para observar estos procesos más amplios y en desarrollo, en los que las comunidades llevan a cabo una búsqueda reflexiva de elementos históricamente apreciados por ellas mismas, convirtiéndolos en un activo comercial que puede entenderse como materia prima o valor agregado. Esta investigación sugiere que insistir en la cultura como materia prima es en realidad caer en las carac- 
terísticas ficticias que encierra la mercancía y no dilucidar las complejas atribuciones fetichistas que contiene. Por otro lado, es más idóneo expresar que la herencia cultural se suma al valor de cambio, ya que se aplica en esa dimensión abstracta en la que los objetos materiales se repletan de cualidades ideológicas.

Esas cualidades abstractas nutren a la mercancía étnica de significados exóticos $u$ originarios, los cuales funcionan en un mercado turístico que jerarquiza estas categorías como insumos apreciados y alcanzables bajo la forma comprable de artesanía, experiencia, tours, entre otros. Aunque es ilusorio asumir que detrás de la atribución de valor agregado hay solo categorías étnicas, cuando en realidad una comunidad como Toconao lleva a cabo un proyecto político-económico distinto, basado en sobredeterminar lo local como marca distintiva frente al escenario comunal y trasnacional.

En este relato se ha propuesto el estudio de la etnomercancía observando el caso del vino de altura de Toconao, una historia de corta data que permite dilucidar los procesos de atribución de significados a la producción indígena, en un mercado donde las categorías étnicas y ambientales llevan un tiempo siendo promovidas. Ahí radica la relevancia de observar momentos recientes donde las transformaciones de la tradi- ción en material turístico están en proceso. Es una tarea donde se manifiesta la política local y la capacidad inventiva de los pueblos originarios, que se tiñe de emprendimiento.

Lo que se observa en Toconao es un fenómeno trasnacional con repercusiones locales, en el cual las áreas productivas apocadas por las consecuencias de los complejos extractivos, se sostienen ahora en el emprendimiento y el fomento externo. Esto último responde a políticas de resarcimiento de las empresas con las comunidades. Aprovechando este impulso, el grupo indígena se vuelve un productor de mercancías "auténticas", en las que depositan sus lineamientos políticos y estrategias económicas. De esta manera, el turismo es visto como vía de desarrollo indígena, como potencial de recuperación territorial y como revitalización de identidades singulares, lo que no anula, sin embargo, el justificado temor a la invasión y la expulsión.

Finalmente, en el sistema turístico de la cuenca del salar se observa una serie de tensiones que no terminan de resolverse, pues aunque existe un notorio crecimiento del protagonismo indígena en la producción mercantil está por verse si su participación intensificará la autonomía local o la sumirá en nuevas formas de dependencia inter y supraétnicas.

\footnotetext{
${ }^{3}$ Desde ya se deben considerar ciertas diferencias conceptuales: la viticultura se refiere al proceso de tratamiento de la vid o parras; la vinicultura es relativa a la vinificación, es decir, la fabricación del vino; finalmente, la vitivinicultura es el proceso completo, desde la uva hasta el producto final.

${ }^{4}$ Una de las labores artesanales reconocidas como tradicionales de Toconao es el esculpido en rocas ígneas, material con el que ciertos artistas respetados del pueblo tallan figuras representativas de la localidad, tales como el ganado auquénido, el campanario de San
} 
Lucas, agricultores llevando cargas de fruta en la espalda, etcétera.

${ }^{5}$ Predomina la producción de varietales franceses como syrah,

\section{Referencias bibliográficas}

Álvarez, L. (2018). Asháninca INC: sobre turismo local y producción de etnomercancías en la Aldea Asháninca San Pedro Marankiari A.C. Chanchamayo, Selva Central. (Tesis inédita de maestría en antropología visual). Pontificia Universidad Católica del Perú, Lima.

Amilhat-Szary, A. \& Guyot, S. (2009). El turismo fronterizo en los Andes centrales: prolegómenos sobre una geopolítica del turismo. $\mathrm{Si}$ Somos Americanos. Revista de Estudios Trasfronterizos, 9(2), 63-109.

Bolados, P. (2014). Procesos transnacionales en el salar de Atacama, norte de Chile: los impactos de la minería y el turismo en las comunidades indígenas atacameñas. Intersecciones en Antropología, 15(2), 431-443.

Bolados, P. \& Boccara, G. (2015). Movilizaciones indígenas y protestas socio-ambientales en el salar de Atacama, norte de Chile. Tessitura, 3(1), 98-120.

Bustos, A. (1999). Etnografía atacameña. Antofagasta: Universidad de Antofagasta.

Bustos, C. (2015). La producción de "etnomercancías" en el contexto turístico atacameño. Líder, (27), 138-171.

Castillo, M., Espinoza, C. \& Campos, L. (2017). Régimen de desigualdad y pueblos indígenas en el período postdictatorial: tres vías en la disputa por la igualdad. Estudios Atacameños, (54), 217-238.

Comaroff, J. \& Comaroff, J. (2009). Ethnicity, INC. Chicago: The University of Chicago Press.

Comisión Verdad Histórica y Nuevo Trato (2003). El pueblo Atacameño (pp. 139-192). En Informe de la Comisión de Verdad Histórica y Nuevo Trato con los Pueblos Indígenas. Versión digital. Santiago: Comisionado Presidencial para Asuntos Indígenas. Recuperado de https://bibliotecadigital.indh.cl/ handle/123456789/268?show=full.

Escalona, J. (2016). Etnomercancía y sobrefetichización: ensayo de mirada estereográfica. Relaciones Estudios de Historia y Sociedad, (148), 259-288.

Fiennes, S. (Dir. y Prod.) (2012). The Pervert's Guide to Ideology [Película]. Holly, K., Rosenbaum, M. \& Wilson, J. (Productores). malbec, petit verdot, chardonnay, aunque se encuentran terruños con injertos de pedro jiménez (España).

Reino Unido: Zeitgeist Films

Fuller, N. (2008). Turismo y cultura: entre el entusiasmo y el recelo. Lima: Pontificia Universidad Católica del Perú.

Gundermann, H. (2004). Inicios de siglo en San Pedro de Atacama: procesos, actores e imaginarios en una localidad andina. Chungara, 36(1), 221-239.

Gundermann, H., González, H. \& Durston, J. (2018). Interetnicidad y relaciones sociales en el espacio atacameño. Estudios Atacameños, (57), 161-179.

Hobsbawm, E. (2012). Introducción: la invención de la tradición (pp. 7-21). En Hobsbawm, E. \& Ranger, T. (Eds.), La invención de la tradición. Barcelona: Crítica.

Jappe, A. (2016). Las aventuras de la mercancía. La Rioja: Pepitas de Calabaza.

Martínez, J. (1998). Pueblos del chañar y el algarrobo: los atacamas en el siglo XVII. Santiago: Dirección de Bibliotecas, Archivos y Museos.

Morales, H. (2016). Etnopolítica atacameña: ejes de la diversidad. Estudios Atacameños, (53), 185-203.

Núñez, M. (2002). Transformaciones culturaes en Toconao por impacto de empresas mineras: un estudio de caso en el norte de Chile. (Tesis inédita de maestría en antropología y desarrollo). Universidad de Chile, Santiago.

Pozo, J. del (2014). Historia del vino chileno: desde la época colonial hasta hoy. Santiago: LOM.

Téllez, E. \& Silva, O. (1989). Atacama en el siglo XVI: la conquista hispana en la periferia de los Andes meridionales. Cuadernos de Historia, (9), 45-69.

Villagrán, C., Castro, V., Sánchez, G., Romo, M., Latorre, C. \& Hinojosa, L. (1998). La tradición surandina del desierto: etnobotánica del área del Salar de Atacama (Provincia de El Loa, Región de Antofagasta, Chile). Estudios Atacameños, (16), 7-105.

Žižek, S. (2003). El sublime objeto de la ideología. Buenos Aires: Siglo XXI. 